\title{
Coordinated Regulation of Arbuscular Mycorrhizal Fungi and Soybean MAPK Pathway Genes Improved Mycorrhizal Soybean Drought Tolerance
}

\author{
Zhilei Liu, ${ }^{1,2}$ Yuanjing Li, ${ }^{1,2}$ Lina Ma, ${ }^{1}$ Haichao Wei, ${ }^{3}$ Jianfeng Zhang, ${ }^{4}$ Xingyuan He, ${ }^{5}$ and Chunjie Tian ${ }^{1}$ \\ ${ }^{1}$ Key Laboratory of Mollisols Agroecology, Northeast Institute of Geography and Agroecology, Chinese Academy of Sciences, \\ Changchun, Jilin 130102, China; ${ }^{2}$ University of Chinese Academy of Sciences, Beijing 100049; ${ }^{3}$ Key Laboratory of Soybean \\ Molecular Design Breeding, Northeast Institute of Geography and Agroecology, Chinese Academy of Sciences, Changchun; \\ ${ }^{4}$ School of Life Sciences, Jilin Agricultural University, Changchun 130118, China; and ${ }^{5}$ Key Laboratory of Wetland Ecology and \\ Environment, Northeast Institute of Geography and Agroecology, Chinese Academy of Sciences, Changchun
}

Submitted 6 July 2014. Accepted 31 October 2014.

\begin{abstract}
Mitogen-activated protein kinase (MAPK) cascades play important roles in the stress response in both plants and microorganisms. The mycorrhizal symbiosis established between arbuscular mycorrhizal fungi (AMF) and plants can enhance plant drought tolerance, which might be closely related to the fungal MAPK response and the molecular dialogue between fungal and soybean MAPK cascades. To verify the above hypothesis, germinal Glomus intraradices (syn. Rhizophagus irregularis) spores and potted experiments were conducted. The results showed that AMF GiMAPKs with high homology with MAPKs from Saccharomyces cerevisiae had different gene expression patterns under different conditions (nitrogen starvation, abscisic acid treatment, and drought). Drought stress upregulated the levels of fungi and soybean MAPK transcripts in mycorrhizal soybean roots, indicating the possibility of a molecular dialogue between the two symbiotic sides of symbiosis and suggesting that they might cooperate to regulate the mycorrhizal soybean drought-stress response. Meanwhile, the changes in hydrogen peroxide, soluble sugar, and proline levels in mycorrhizal soybean as well as in the accelerated exchange of carbon and nitrogen in the symbionts were contributable to drought adaptation of the host plants. Thus, it can be preliminarily inferred that the interactions of MAPK signals on both sides, symbiotic fungus and plant, might regulate the response of symbiosis and, thus, improve the resistance of mycorrhizal soybean to drought stress.
\end{abstract}

Arbuscular mycorrhizal (AM) symbiosis represents a unique association between the mycelium of a mycorrhizal fungus and more than $80 \%$ of higher plant families. The AM fungus, an obligate biotroph belonging to the phylum Glomeromycota (Schüßler et al. 2001), receives carbohydrates required to complete its life cycle from the host plant; in exchange, it provides the plant with nutrients such as N, P, and microelements, with some transporters involved in $\mathrm{C}$ and nutrition transport, such as sucrose transporters from host plants and

\section{Z. Liu, Y. Li, and L. Ma contributed equally to the article.}

Corresponding author: C. Tian; E-mail: tiancj@ neigae.ac.cn

*The $e$-Xtra logo stands for "electronic extra" and indicates that three supplementary tables are published online.

() 2015 The American Phytopathological Society ammonium transporters from fungi (Aldape et al. 2003; Allen 2007; Govindarajulu et al. 2005; Perez-Moreno and Read 2001; Pérez-Tienda et al. 2011; Tian et al. 2010). AM symbiosis can protect host plants against the detrimental effects of various biotic and abiotic stresses (Liu et al. 2013; Ruiz-Lozano et al. 2006; Yang et al. 2014). Drought stress is considered to be one of the most important abiotic factors limiting plant growth and yield in many areas (Ahuja et al. 2010; Yang et al. 2010). The contributions of mycorrhiza to the drought tolerance of host plants primarily relates to physical, nutritional, physiological, and cellular factors (Ruiz-Lozano 2003). For instance, the symbiotic arbuscular mycorrhizal fungi (AMF) can alter the osmotic adjustment ability and leaf water potential of host plants, thereby reducing the oxidative damage caused by reactive oxygen species (ROS) under drought conditions and affecting the free amino acids and sugar concentrations of the roots of host plants (Abbaspour et al. 2012; Lee et al. 2012b; Ruiz-Lozano 2003). Additionally, the presence of AMF can improve symbiont water flow by regulating the levels of aquaporin expression in both the host plant and the AMF (Bárzana et al. 2014; Li et al. 2013a).

During the long process of evolution, plants have evolved a common set of adaptive mechanisms involved in resistance to environmental stresses, ranging from sensing pressure signals to activating various series of physiological and biochemical changes (Umezawa et al. 2006). Among the numerous signaling pathways, the mitogen-activated protein kinase (MAPK) cascades regulate myriad cellular and physiological processes and are activated by a range of different stimuli, including wounding, various elicitors, abiotic and biotic stresses, and phytohormones (Colcombet and Hirt 2008; Pitzschke et al. 2009a). The MAPK-related signal transduction system is composed of three kinase modules (MAPK kinase kinase, MAPK kinase, and MAPK) which are linked in various ways to upstream receptors and downstream targets (Jonak et al. 2002). It has been reported that drought stress is associated with the expression of certain $M A P K$ genes, such as AtMPK4 and AtMPK6 in Arabidopsis thaliana (Droillard et al. 2002; Matsuoka et al. 2002). In rice (Oryza sativa), the expression of OsMPK5 was increased by overexpression or inhibited by RNA interference (RNAi) in transgenic rice plants, and corresponding changes in coldness, drought, and $\mathrm{NaCl}$ tolerances were reported (Xiong and Yang 2003). However, studies of MAPK genes on soybean growth under drought stress still need further investigation. 
In fungi, the study of MAPKs from Saccharomyces cerevisiae has provided pivotal insights that have contributed greatly to our understanding of MAPK signaling in all eukaryotes because these pathways are highly conserved (Chen and Thorner 2007; Hamel et al. 2012). Genome-scale transcriptome studies show that MAPK genes are relatively highly expressed in the free-living mycelium, fruiting bodies, and ectomycorrhiza compared with other conserved genes (Martin et al. 2008, 2010), indicating that these signaling pathways likely contribute to the development and function of the symbiotic association. To date, the functions of AM fungal MAPK genes have received less attention than the functions of plant MAPK genes. In particular, the mechanisms governing the interactions of MAPK signals on both sides of a symbiotic fungus-plant relationship require further deep exploration. In the study of AMF-plant interaction, the relevant data show only that AMF exudates could activate MAPKs in plant cells or that AMF colonization induced $M A P K$ gene expression in host roots (Francia et al. 2011; Gallou et al. 2010). However, the recent report of nonredundant virtual transcripts from the fungus Glomus intraradices confirmed the presence and expression of several MAPK signaling components (Tisserant et al. 2012), and the transcriptional cDNA sequence is now available for G. intraradices (Tisserant et al. 2013), which has allowed the functional analysis of the complement of MAPK signaling components in AMF.

There is evidence showing that, during interactions between phytopathogenic fungi and plants, MAPK cascades in the two organisms do not operate independently but, instead, mutually contribute to a highly interconnected molecular dialogue between the plant and the fungus. Consequently, some pathogenesisrelated processes controlled by fungal MAPKs lead to the activation of plant signaling, including the recruitment of plant MAPK cascades. Conversely, plant MAPKs promote defense mechanisms that threaten the survival of fungal cells, leading to a stress response mediated, in part, by fungal MAPK cascades (Hamel et al. 2012). However, it is still unclear whether the MAPK pathways of host plants and mycorrhizal fungi coordinate to ultimately enhance host plant stress tolerance such as of drought, and the physiological and biochemical processes involved in these interactions remain unknown.

In this study, the AMF cDNA sequences with high homologies with reported fungal $M A P K$ genes were selected, and expression levels in AM-germinated spores treated with different conditions ( $N$ starvation, exogenous application of abscisic acid [ABA], and drought stress) were investigated to explore the MAPK response strategy of nonsymbiotic AMF under different conditions. The reasons for selecting $\mathrm{N}$ and $\mathrm{ABA}$ were that $\mathrm{N}$ is the main nutrition transferred from fungi to host plant in AM symbiosis and ABA is important in drought response of mycorrhizal plants; therefore, it is interesting and meaningful to investigate their impacts on the expression of fungal MAPK genes (Aroca et al. 2008; Lee et al. 2012a; Nakashima et al. 2014; Tian et al. 2010). Meanwhile, potted nonmycorrhizal and mycorrhizal soybean plants (Glycine max) growing under well-watered and drought-stress conditions were used to investigate drought-stress-related responses involving soybean and AMF MAPKs, mycelium colonization and development in soybean, and characteristic physiological and biochemical changes in the soybean plants. The major aims of this work were to (i) examine the expression of several candidate GiMAPK genes under different conditions, based on the AMF cDNA sequence database and (ii) explore the mechanisms of the molecular dialogue between fungal and host plants' MAPK signaling pathways and the interactions between the two organisms in the role of host plants' resistance to drought stress.

\section{RESULTS}

\section{Changes in plant physiological parameters under drought stress.}

No mycorrhizal colonization was observed in the noninoculated soybean. Among inoculated soybean plants, the mycorrhizal colonization frequency $(\mathrm{F} \%)$ was $58 \%$ under normal conditions but decreased to $41 \%$ under drought-stress conditions. However, there was no significant change in the intensity of mycorrhizal colonization in mycorrhizal root fragments $(\mathrm{m} \%)$ and arbuscule abundance in mycorrhizal parts of root fragments (a\%) (Table 1). In addition, significantly fewer mycorrhizal entry points were observed under drought conditions than under normal conditions. Drought stress significantly reduced mycorrhizal colonization but significantly increased the numbers of arbuscules and vesicles per unit length of mycorrhizae.

A comparison of mycorrhizal and nonmycorrhizal soybean revealed significant differences in soybean growth, with significantly greater plant height, root length, root surface area, and shoot and root fresh weight in mycorrhizal soybean than in nonmycorrhizal soybean under both normal and stress conditions (Table 2). Moreover, drought stress decreased nonmycorrhizal soybean plant height, root length, root surface, fresh weight, and shoot dry weight but appeared to have little effect on mycorrhizal soybean root length and root surface. However, there was no interaction between water and AMF inoculation in soybean growth parameters, except for root fresh weight.

Relative water content (RWC) is an important indicator that reflects the physiological condition of moisture in plant tissues. Under normal conditions, the RWC of mycorrhizal soybean leaves was similar to the RWC of nonmycorrhizal soybean leaves (Table 2). Exposure to drought stress for 10 days significantly decreased the RWC in both types of soybean leaves but the RWC was significantly higher in leaves from mycorrhizal soybean plants than in leaves from nonmycorrhizal soybean plants.

Trypan blue staining produced significantly more spots on the leaves from nonmycorrhizal soybean plants than on leaves from mycorrhizal soybean plants under drought condition (Fig. 1A). These results suggested that more drought-induced cell death occurred in nonmycorrhizal soybean leaves than in mycorrhizal soybean leaves. Therefore, mycorrhizal soybean plants were less damaged by drought than nonmycorrhizal soybean plants.

Table 1. Arbuscular mycorrhizal colonization in soybean plants inoculated with Glomus intraradices under well-watered (WAM) and drought-stressed conditions $(\mathrm{DAM})^{\mathrm{z}}$

\begin{tabular}{|c|c|c|c|c|c|c|}
\hline Conditions & $\mathbf{F} \%$ & $\mathbf{m} \%$ & $\mathbf{a} \%$ & Entry points (number/cm) & Arbuscules (number/cm) & Vesicles (number/cm) \\
\hline WAM & $58.1 \pm 5.6 \mathrm{a}$ & $32.5 \pm 2.8 \mathrm{a}$ & $43.6 \pm 3.5 \mathrm{a}$ & $8.6 \pm 1.2 \mathrm{a}$ & $3.6 \pm 0.6 b$ & $2.4 \pm 0.4 b$ \\
\hline DAM & $41.3 \pm 4.7 b$ & $33.1 \pm 1.9 \mathrm{a}$ & $47.2 \pm 2.4 \mathrm{a}$ & $5.3 \pm 0.7 b$ & $5.5 \pm 0.4 \mathrm{a}$ & $4.5 \pm 0.5 \mathrm{a}$ \\
\hline
\end{tabular}

${ }^{\mathrm{z}} \mathrm{F} \%=$ frequency of mycorrhiza in mycorrhizal root fragments, $\mathrm{m} \%=$ intensity of the mycorrhizal colonization in mycorrhizal root fragments, a $\%=$ arbuscule abundance in mycorrhizal parts of root fragments Values are means $(n=3) \pm$ standard errors. Means followed by different letters are significantly different within each treatment $(P<0.05)$. 
Changes of hydrogen peroxide concentration

in soybean under drought stress.

To examine drought-stress-induced ROS production in soybean, hydrogen peroxide $\left(\mathrm{H}_{2} \mathrm{O}_{2}\right)$ accumulation was quantitatively assessed using diaminobenzidine (DAB) (Fig. 1B) and qualitatively assessed by absorption peaks using ultraviolet spectrophotometry (Fig. 2A and B). Under normal conditions, the $\mathrm{H}_{2} \mathrm{O}_{2}$ concentration was higher in the mycorrhizal soybean leaves than in the nonmycorrhizal soybean leaves. Drought stress induced a surge of $\mathrm{H}_{2} \mathrm{O}_{2}$ in both types of soybean leaves; however, there were no significant differences between the $\mathrm{H}_{2} \mathrm{O}_{2}$ concentrations of drought-treated mycorrhizal and nonmycorrhizal soybean leaves (Fig. 2A). The $\mathrm{H}_{2} \mathrm{O}_{2}$ accumulation patterns in soybean roots were similar to the $\mathrm{H}_{2} \mathrm{O}_{2}$ accumulation patterns in soybean leaves. In particular, drought induced a significant increase in $\mathrm{H}_{2} \mathrm{O}_{2}$ in soybean roots; however, the $\mathrm{H}_{2} \mathrm{O}_{2}$ concentration was lower in the roots of mycorrhizal soybean than in the roots of nonmycorrhizal soybean (Fig. 2B). These data suggest that mycorrhizal inoculation induced $\mathrm{H}_{2} \mathrm{O}_{2}$ accumulation under normal conditions but inhibited the excessive accumulation of $\mathrm{H}_{2} \mathrm{O}_{2}$ caused by oxidative bursts during drought conditions.

\section{Effects of drought stress on concentrations \\ of osmoregulatory substances}

in nonmycorrhizal and mycorrhizal soybean.

Under normal conditions, mycorrhizal and nonmycorrhizal soybean leaves exhibited similar levels of soluble sugar. Drought stress significantly increased the soluble sugar concentration of nonmycorrhizal soybean leaves but did not significantly affect the soluble sugar concentration of mycorrhizal soybean leaves (Fig. 3A). Under normal conditions, the soluble sugar concentration was higher in mycorrhizal soybean roots than in nonmycorrhizal soybean roots. Drought conditions induced a significant increase in the soluble sugar concentration in soybean roots, and mycorrhizal soybean roots had a higher concentration than that in nonmycorrhizal soybean roots (Fig. 3B). Drought conditions also induced the accumulation of proline in soybean plants. In leaves, drought conditions caused significant increases in proline concentration, with higher proline levels observed in nonmycorrhizal soybean leaves than in mycorrhizal soybean leaves (Fig. 3C). In contrast, in the roots, significantly higher proline concentrations were observed in mycorrhizal soybean than in nonmycorrhizal soybean (Fig. 3D). These data suggest, that under drought conditions, greater quantities of soluble osmoregulatory substances accumulated in mycorrhizal soybean roots than in nonmycorrhizal soybean roots.

\section{Exchange of $\mathbf{C}$ and $\mathbf{N}$ crosstalk}

between AMF and soybean under drought stress.

Under normal conditions, higher transcript levels of the soybean sucrose transporter GmSUT1, which played a crucial role in transporting sucrose (Aldape et al. 2003), was observed in the mycorrhizal soybean roots compared with the nonmycorrhizal soybean roots (Fig. 4A). In nonmycorrhizal soybean roots, drought conditions did not induce significant changes in GmSUT1 transcription levels. In contrast, drought treatment enhanced GmSUT1 transcription in mycorrhizal soybean roots (Fig. 4A). Fungal glutamine synthetase (GiGS) and ammonium transporter (GiAMT) are genes involved in $\mathrm{N}$ transport in the fungi (Tian et al. 2010; Pérez-Tienda et al. 2011). It was found that the transcription levels of GiGS1 and GiAMT2 were increased under drought conditions as well (Fig. $4 \mathrm{~B}$ and $\mathrm{C}$ ).

\section{Homologous and phylogenetic analysis of MAPK genes in AMF.}

Because the study of MAPKs from $S$. cerevisiae has contributed greatly to our understanding of MAPK signaling in all eukaryotes, including mycorrhizal fungi, we chose six yeast MAPKs (Sce-Kss1, Sce-Fus3, Sce-Slt2, Sce-Hog1, Sce-Smk1, and Sce-Ime2) to analyze the homology between yeast and AMF. Based on the protein sequences from yeast, we used BLASTp in the Glomus intraradices database in the National Center for Biotechnology Information (NCBI), from which we found five candidate genes, and the details of BLASTp results were listed in Supplementary Table S1. According to the amino
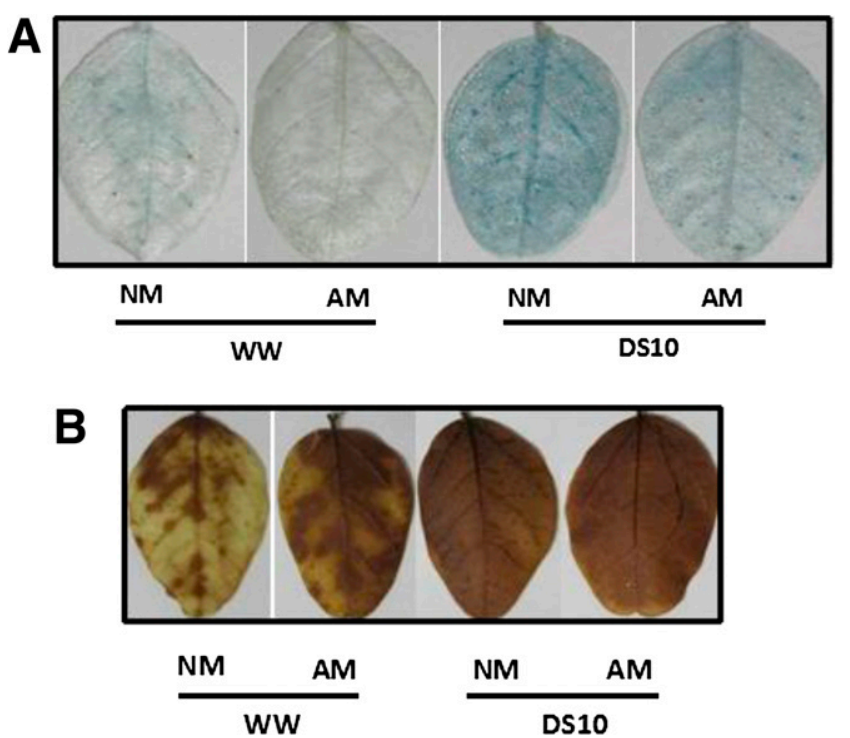

Fig. 1. A, Cell death in leaves of soybean (Glycine max) and B, representative photographs showing the accumulation of $\mathrm{H}_{2} \mathrm{O}_{2}$ in leaves subjected to drought for 10 days, as measured by histochemical staining with diaminobenzidine (DAB). $\mathrm{NM}=$ nonmycorrhizal soybean, $\mathrm{AM}=$ mycorrhizal soybean, $\mathrm{WW}=$ well-watered condition, and DS10 $=$ drought-stressed condition for 10 days.

Table 2. Plant growth parameters of soybean (Glycine max) plants under different conditions ${ }^{\mathrm{y}}$

\begin{tabular}{|c|c|c|c|c|c|c|c|c|}
\hline \multirow[b]{2}{*}{ Conditions } & \multirow[b]{2}{*}{ Plant height $(\mathrm{cm})$} & \multirow[b]{2}{*}{ Root length $(\mathbf{c m})$} & \multirow[b]{2}{*}{ Root surface $\left(\mathrm{cm}^{2}\right)$} & \multicolumn{2}{|c|}{ Fresh weight $\left(\mathrm{g} \mathrm{plant}^{-1}\right)$} & \multicolumn{2}{|c|}{ Dry weight $\left(\right.$ g plant $\left.^{-1}\right)$} & \multirow[b]{2}{*}{ RWC (\%) } \\
\hline & & & & Shoots & Roots & Shoots & Roots & \\
\hline WNM & $31.7 \pm 0.5 b$ & $19.3 \pm 0.7 b$ & $22.1 \pm 0.5 b$ & $9.0 \pm 0.2 b$ & $2.5 \pm 0.2 b$ & $2.2 \pm 0.1 \mathrm{a}$ & $0.4 \pm 0.0 \mathrm{a}$ & $87.6 \pm 1.9 a$ \\
\hline DNM & $25.0 \pm 0.7 \mathrm{c}$ & $15.0 \pm 0.8 \mathrm{c}$ & $16.6 \pm 1.0 \mathrm{c}$ & $6.5 \pm 0.5 \mathrm{~d}$ & $1.8 \pm 0.1 \mathrm{c}$ & $1.7 \pm 0.1 \mathrm{~b}$ & $0.3 \pm 0.0 \mathrm{a}$ & $68.4 \pm 1.3 \mathrm{c}$ \\
\hline WAM & $33.7 \pm 0.6 \mathrm{a}$ & $24.9 \pm 0.9 \mathrm{a}$ & $31.5 \pm 0.8 \mathrm{a}$ & $10.6 \pm 0.4 \mathrm{a}$ & $3.1 \pm 0.2 \mathrm{a}$ & $2.6 \pm 0.1 \mathrm{a}$ & $0.5 \pm 0.1 \mathrm{a}$ & $89.2 \pm 0.7 a$ \\
\hline DAM & $29.9 \pm 1.0 \mathrm{~b}$ & $22.7 \pm 1.6 \mathrm{a}$ & $29.7 \pm 1.2 \mathrm{a}$ & $8.2 \pm 0.6 \mathrm{c}$ & $2.6 \pm 0.1 \mathrm{~b}$ & $2.0 \pm 0.2 b$ & $0.4 \pm 0.1 \mathrm{a}$ & $79.5 \pm 1.0 \mathrm{~b}$ \\
\hline Water $^{\mathrm{z}}$ & $*$ & ns & ns & $*$ & $*$ & $*$ & ns & $*$ \\
\hline AMF & $*$ & $*$ & $*$ & $*$ & $*$ & $\mathrm{~ns}$ & ns & ns \\
\hline Water $\times$ AMF & ns & ns & ns & ns & $*$ & $\mathrm{~ns}$ & ns & ns \\
\hline
\end{tabular}

${ }^{y}$ WNM = well-watered nonmycorrhizal soybean, DNM = drought-stressed nonmycorrhizal soybean, WAM = well-watered mycorrhizal soybean, DAM = drought-stressed mycorrhizal soybean, and RWC $=$ relative water content. Values are means $(n=3) \pm$ standard errors. Means followed by different letters are significantly different within each treatment $(P<0.05)$.

z Analysis of variance output: * indicates $P<0.05$ and ns $=$ not significant. 
acid alignment analysis, GiMAPKs were found to possess a high similarity with MAPKs from $S$. cerevisiae, especially for the conserved region (Fig. 5A). Furthermore, they have the same conserved domain structures ( $\mathrm{S}-\mathrm{TKc})$, supporting the conservation of functions of MAPKs between AMF and S. cerevisiae.

The alignments of the GiMAPK sequences were then used to calculate a phylogenetic tree (Fig. 5B), from which four

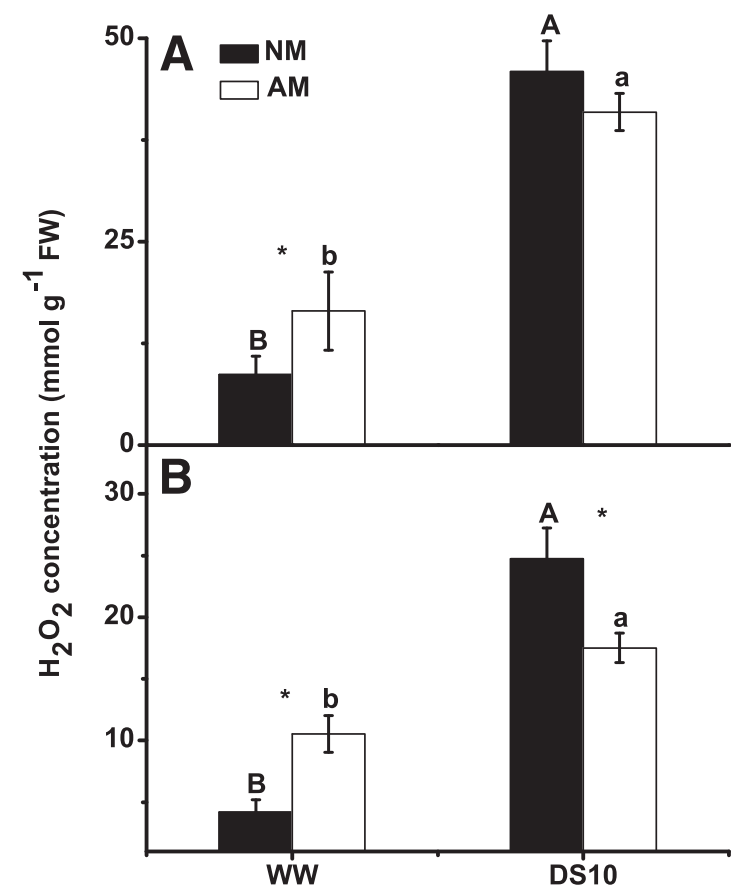

Fig. 2. $\mathrm{H}_{2} \mathrm{O}_{2}$ concentrations in $\mathbf{A}$, leaves and $\mathbf{B}$, roots of soybean (Glycine max $)$. $\mathrm{NM}=$ nonmycorrhizal soybean, $\mathrm{AM}=$ mycorrhizal soybean, $\mathrm{WW}=$ well-watered condition, and DS10 = drought-stressed condition for 10 days Means followed by the same letter are not significantly different within each treatment. Asterisks indicate significant differences between treatments. Values are means $(n=3) \pm$ standard errors. Means were compared with Duncan's multiple-range test at the $P<0.05$ level. orthologous between $G$. intraradices and $S$. cerevisiae could be distinguished. GiMAPK1, GiMAPK2, and GiMAPK5 are the orthologs of Sce-Hog1, Sce-Kss1, and Sce-Ime2, respectively, and GiMAPK3 and GiMAPK4 were orthologous with Sce-Slt2. However, the orthologs of Sce-Fus3 and Sce-Smk1 were not found in these data.

\section{Effects of different abiotic stresses} on the expression of GiMAPKs genes.

To investigate the responses of GiMAPK candidates under different conditions, the transcript levels of GiMAPKs were measured by quantitative real-time polymerase chain reaction (qRT-PCR). The changes in the GiMAPK expression levels varied between conditions: $\mathrm{N}$ starvation condition (LN treatment) induced the expression of GiMAPK1, GiMAPK2, and GiMAPK3, of which GiMAPK2 was most highly expressed (Fig. 6A). A similar result was obtained after exogenous application of ABA (ABA treatment) (Fig. 6B). However, under drought conditions (polyethylene glycol [PEG] treatment), higher GiMAPK1 and GiMAPK3 gene expression levels were observed and GiMAPK1 was the dominant gene (Fig. 6C). GiMAPK4 and GiMAPK5 appeared to be insensitive to these three conditions; their deeper functions require further exploration.

\section{GmMAPK and GiMAPK gene expression patterns in nonmycorrhizal and mycorrhizal soybean under drought stress.}

The expression patterns of MAPKs in soybean and AMF were analyzed in the potted experiment. For GmMAPKs, under normal conditions (well-watered condition), the expression levels of GmMAPK2, GmMAPK3-2, GmMAPK4-2, and GmMAPK5 were higher in mycorrhizal soybean roots than in nonmycorrhizal soybean (Fig. 7). Under drought-stress conditions, the expression levels of GmMAPK2 and GmMAPK5 were increased in nonmycorrhizal soybean roots, whereas GmMAPK2, GmMAPK3-2, and GmMAPK5 transcript levels were increased in mycorrhizal soybean roots, and mycorrhizal soybean showed a higher $M A P K$ gene expression level than that in nonmycorrhizal soybean. Moreover, the expression level of GmMAPK4-1 was reduced in both nonmycorrhizal and mycorrhizal soybean roots
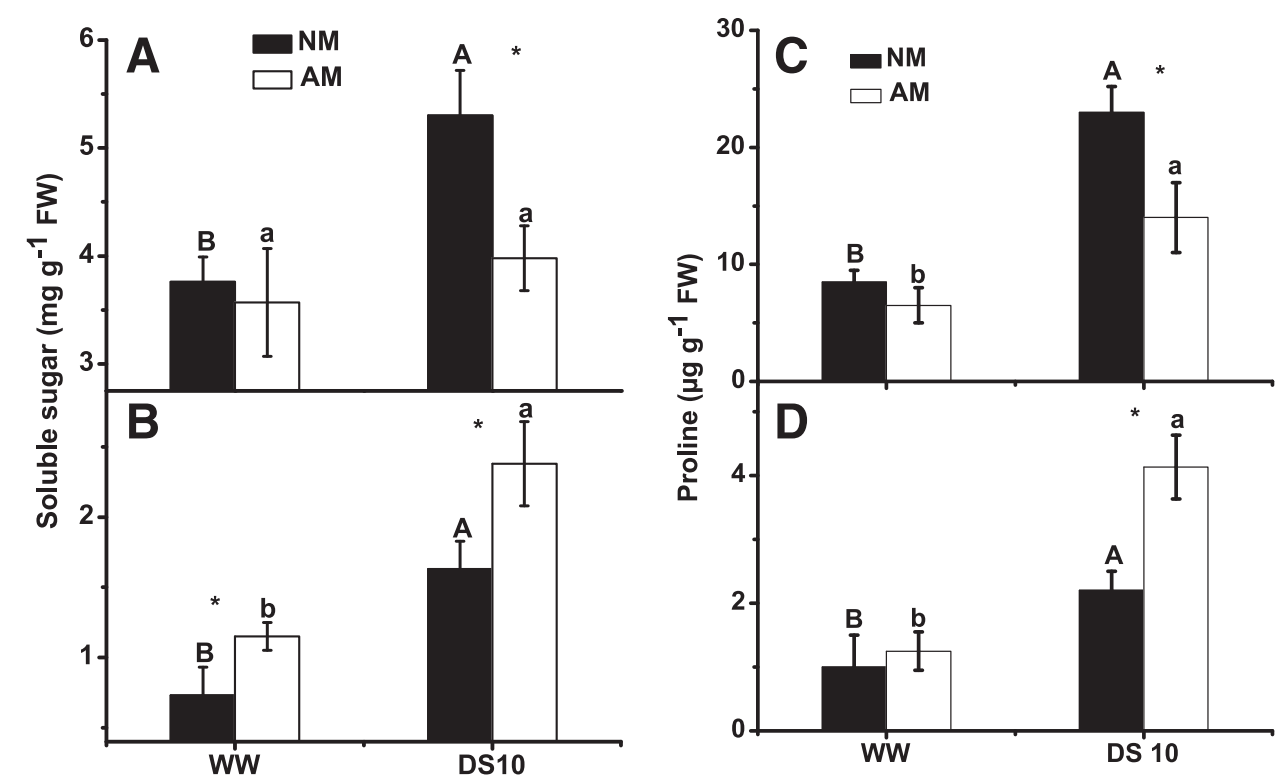

Fig. 3. Soluble sugar concentrations in $\mathbf{A}$, leaves and $\mathbf{B}$, roots and proline concentration in $\mathbf{C}$, leaves and $\mathbf{D}$, roots of soybean $(G l y c i n e ~ m a x)$. NM = nonmycorrhizal soybean, AM = mycorrhizal soybean, WW = well-watered condition, and DS $10=$ drought-stressed condition for 10 days. Means followed by the same letter are not significantly different within each treatment. Asterisks indicate significant differences between treatments. Values are means $(n=3) \pm$ standard errors. Means were compared with Duncan's multiple-range test at the $P<0.05$ level. 
upon drought stress (Fig. 7). It could be found that the interaction of mycorrhization and drought stress affected the expression level of GmMAPK2 and GmMAPK5 (Supplementary Table S2). For GiMAPKs, drought stress stimulated the expression of GiMAPK1 and GiMAPK3 in fungi, and GiMAPK1 appeared to be the dominant gene (Fig. 8). Results of two-way analysis of variance (ANOVA) showed that mycorrhization induced the expression of GiMAPK1, GiMAPK3, and GiMAPK4, and there existed the interaction of mycorrhization and drought stress on the transcript level of GiMAPK1.

\section{DISCUSSION}

\section{The involvement of soybean MAPK}

in the response to drought stress.

Under drought-stress conditions, plants receive and transduce drought-stress signals to regulate the expression of relevant genes and, thereby, adjust their metabolic responses to adapt to the stress. Studies have demonstrated that drought stress can activate $M A P K$ genes and that these genes play important roles in regulating immune responses to drought (Huang et al. 2011). We determined that drought stress affected the expression of the soybean MAPK genes, GmMAPKs. After 10 days of drought stress, the expression levels of GmMAPK2 and $G m M A P K 5$ were significantly upregulated in nonmycorrhizal

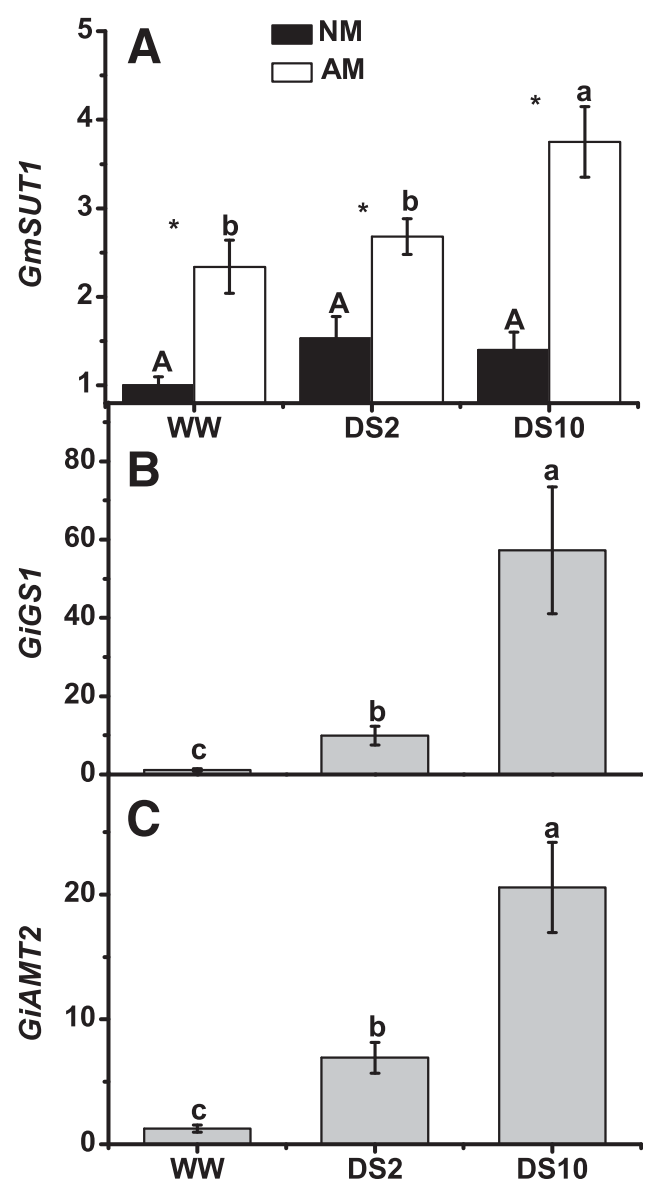

Fig. 4. Relative expression levels of soybean (Glycine max) A, GmSUT1; $\mathbf{B}$, GiGS1; and $\mathbf{C}$, GiAMT2 in soybean roots. NM = nonmycorrhizal soybean, $\mathrm{AM}=$ mycorrhizal soybean, $\mathrm{WW}=$ well-watered condition, $\mathrm{DS} 2=$ drought-stressed condition for 2 days, and DS10 = drought-stressed condition for 10 days. Means followed by the same letter are not significantly different within each treatment. Asterisks indicate significant differences between treatments. Values are means $(n=3) \pm$ standard errors. Means were compared with Duncan's multiple-range test at the $P<0.05$ level. soybean roots (Fig. 7). However, drought stress significantly decreased the transcript levels of GmMAPK3-1 and GmMAPK4-1. A previous report showed that homologs of Arabidopsis MPK4 in soybean were negative regulators of defense responses to diseases such as downy mildew and Soybean mosaic virus and positive regulators of plant development and growth (Liu et al. 2011). Combining the present results with those of the previous study suggests that GmMAPK4 might have responses to drought stress similar to those to disease stress; however, the details of GmMAPK4 under drought stress require further investigation.

Oxidative bursts are a rapid defense response in plants, and excessive $\mathrm{H}_{2} \mathrm{O}_{2}$ accumulation can damage plants. Consequently, plants must maintain a relatively low level of ROS to minimize the cell damage caused by oxidative stress (Foyer and Shigeoka 2011; Harb et al. 2010). ROS accumulation is dependent on the equilibrium between the generation and removal of these oxygen species (Buchanan and Balmer 2005; Pitzschke et al. 2009b). As important signaling molecules in biological defense responses, ROS are MAPK activators that induce the expression of a series of defense-related genes that allow cells to respond to hostile environmental conditions. Previous studies have demonstrated that $\mathrm{H}_{2} \mathrm{O}_{2}$ can activate MAPK activity in a concentration-dependent manner (Rentel et al. 2004; Zhang et al. 2006). For example, ABA-induced $\mathrm{H}_{2} \mathrm{O}_{2}$ production can promote $M A P K$ expression in corn (Zhang et al. 2006), and the MAPK signaling pathway regulates NO and NADPH oxidasedependent oxidative bursts in tobacco (Asai et al. 2008). Meanwhile, $M A P K$ overexpression can promote the activation of antioxidant defense systems, resulting in the reduction of $\mathrm{H}_{2} \mathrm{O}_{2}$ levels in plants (Im et al. 2012). The results of the current study indicated the trends in the changes in soybean $M A P K$ gene expression and $\mathrm{H}_{2} \mathrm{O}_{2}$ levels that occur under drought conditions. These results demonstrated that drought stress induced the expression of two MAPK genes, GmMAPK2 and $G m M A P K 5$, and that $\mathrm{H}_{2} \mathrm{O}_{2}$ levels were higher under drought conditions than under normal conditions (Fig. 2), suggesting a role for crosstalk between MAPK and $\mathrm{H}_{2} \mathrm{O}_{2}$.

Soluble sugars and proline are important plant osmolytes. These molecules can function as osmoprotectants that safeguard biological macromolecules from solute-related effects. In addition, in plants, proline not only regulates redox reactions, thereby influencing the storage and transfer of energy, but also acts as an electron donor that can regenerate nicotinamide adenine dinucleotide phosphate $\left(\mathrm{NADP}^{+}\right)$to prevent the generation of ROS (Sharma and Verslues 2010; Szabados and Savouré 2010; Verslues and Sharma 2010). Under drought stress, nonmycorrhizal soybean plants accumulate soluble sugars and proline (Fig. 3), indicating that these plants have initiated immune responses that enhance their drought tolerance.

\section{The self-protective strategies of the AMF under stress conditions.}

The MAPK signal transduction pathway plays important regulatory roles in the growth, development, successful infection, and stress resistance of fungi (Hamel et al. 2012; Rispail et al. 2009; Zhao et al. 2007). Six MAPKs are encoded by the yeast genome, which has been fully sequenced. Five of them have been assigned to specific pathways involved in mating, filamentation, adaptation to osmotic stress, cell wall remodeling, and sporulation (Hamel et al. 2012; Madhani and Fink 1998). Additionally, three types of MAPK pathways that affect mycelial growth, osmotic stress adaptation, and the host infection process have been discovered in Magnaporthe grisea (Dixon et al. 1999; Hamel et al. 2012; Idnurm and Howlett 2001). In this work, five AM fungal GiMAPK candidates were selected from a $G$. intraradices database, and an analysis of sequence homology of the predicted amino acid sequences 
suggests that AMF MAPK candidates have relatively high homology with MAPKs from S. cerevisiae, particularly in the conserved domain region. Furthermore, based on the phylogenetic tree constructed from the sequence alignment, GiMAPKs are orthologous with $S$. cerevisiae (Fig. 5). However, the gene transcript pattern and function of each GiMAPK gene remained unknown. Therefore, we preliminarily characterized the expression of the GiMAPK genes in response to different conditions, including $\mathrm{N}$ starvation, hormone application (ABA), and drought stress (PEG treatment), with mycorrhizal fungi spores. These results showed that GiMAPK genes demonstrated different transcript patterns under different conditions. For example, under $\mathrm{N}$ starvation and hormone application conditions, GiMAPK2 was the dominant gene whereas, under drought conditions, GiMAPK1 appeared to be the dominant gene (Fig. 6). In this work, GiMAPK3 was more sensitive to the change of environment than GiMAPK4 and GiMAPK5, whereas the deeper functions of GiMAPKs under different conditions require further examination.
It has been reported that MAPK pathways in plants participate in the symbiotic infection by mycorrhizal fungi and fulfill important functions during infection processes (Hamel et al. 2012; Menotta et al. 2006; Peter et al. 2003). The expression levels of GiMAPK in mycorrhizal soybean were analyzed, demonstrating that the MAPK pathway was induced in soybean under drought conditions. For the AMF under drought stress, the MAPK genes GiMAPK1 and GiMAPK3 were stimulated as well (Fig. 8), and this enhanced $M A P K$ expression was accompanied by increases in the numbers of vesicles and arbuscules in the root cells of infected soybean plants (Table 1). This finding indicated that fungal $M A P K$ expression is both involved in mycelium growth and infection processes and associated with drought adaptation characteristics. In fact, it has been reported that $M A P K$ expression plays a role not only in the mycorrhizal colonization process but also in the coordinated interactions between the symbiotic partners during the infection stage (Hamel et al. 2012; Martin et al. 2008; Tisserant et al. 2012). However, to date, only limited research has addressed

A
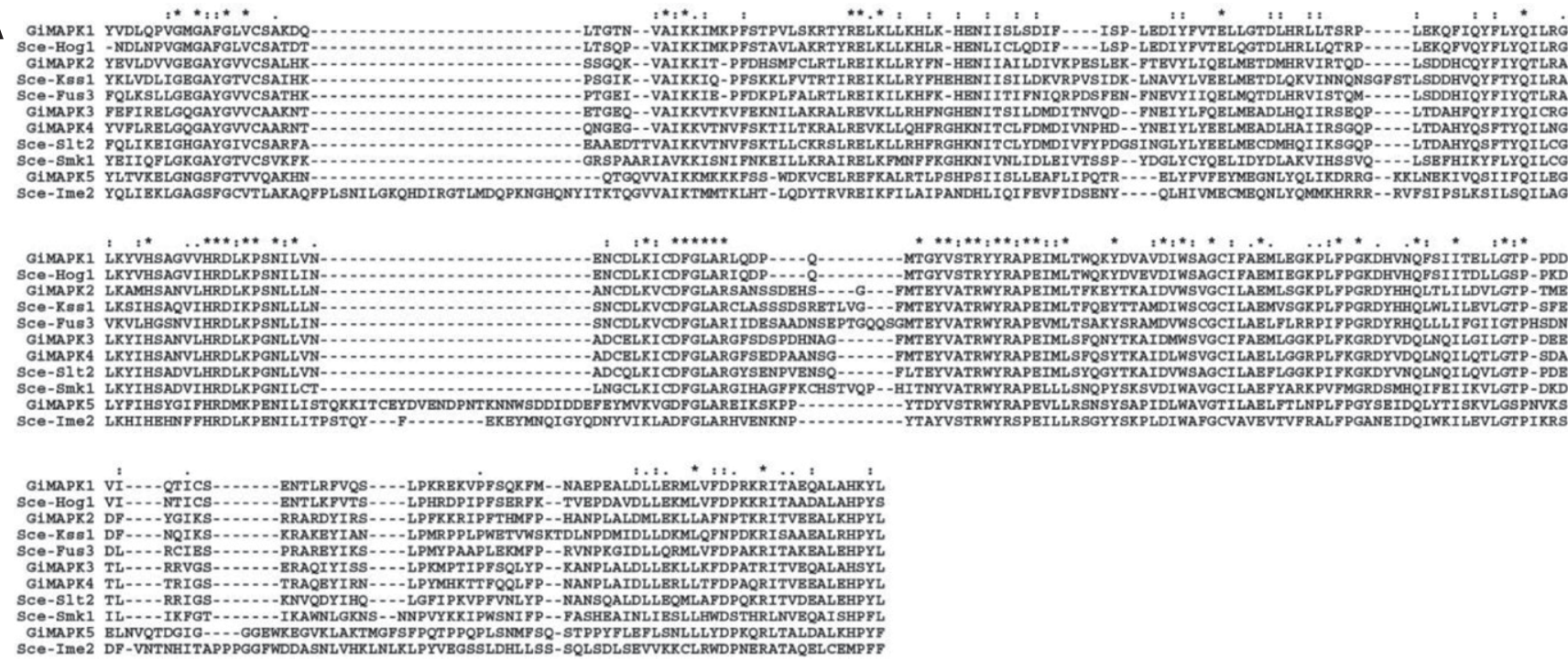

B

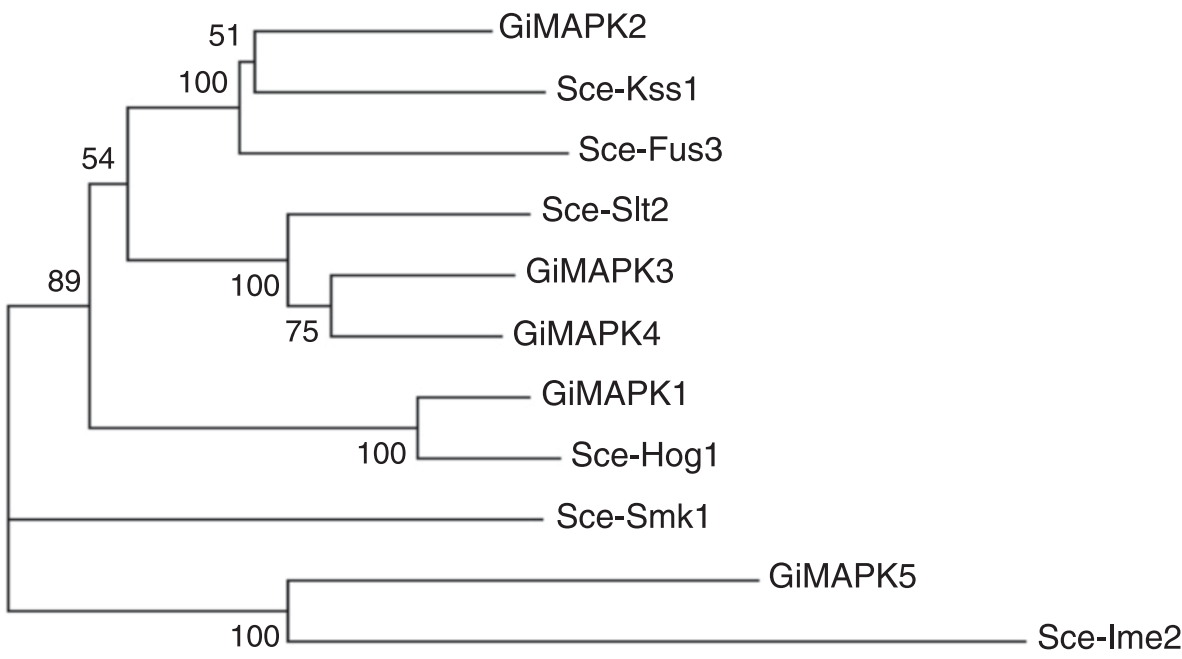

0.1

Fig. 5. A, Alignment of the GiMAPKs from Glomus intraradices with mitogen-activated protein kinases (MAPKs) from Saccharomyces cerevisiae and B, the phylogenetic relationships of GiMAPKs to the MAPKs from S. cerevisiae. Protein sequences shown in these diagrams are listed in GenBank database under the following accession numbers: GiMAPK1 (ESA14053), GiMAPK3 (ESA20482), GiMAPK4 (ESA18300), GiMAPK5 (ERZ99968), GiMAPK6 (ESA12361), Sce-Fus3 (YBL016W), Sce-Kss1 (YGR040W), Sce-Slt2 (YHR030C), Sce-Smk1 (YPR054W), Sce-Hog1 (YLR113W), and Sce-Ime2 (YJL106W). 
the functions of MAPK signaling in symbiotic fungi. The preliminary results of this article have merely demonstrated that, under drought stress, MAPK in symbiotic fungi may be involved in the regulation of fungal infection and changes in fungal morphology; however, further detailed investigation of this issue is required to address the questions of how this
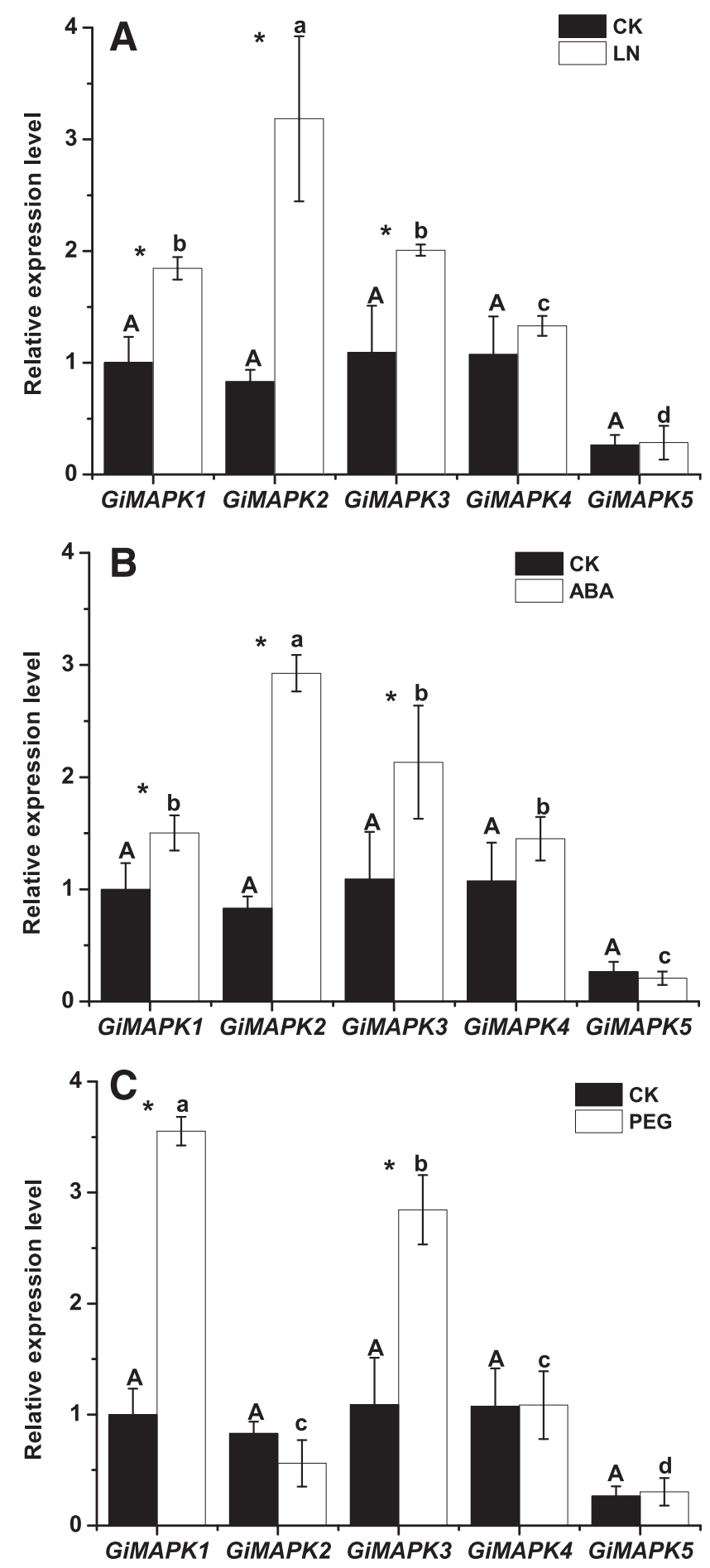

Fig. 6. Relative expression levels of GiMAPKs from Glomus intraradices spores under $\mathbf{A}, \mathbf{N}$ starvation (LN); B, abscisic acid (ABA) application (ABA); and $\mathbf{C}$, drought stress (polyethylene glycol [PEG]) conditions. $\mathrm{CK}=$ control treatment. Means followed by the same letter are not significantly different within each treatment. Asterisks indicate significant differences between treatments. Values are means $(n=3) \pm$ standard errors. Means were compared with Duncan's multiple-range test at the $P<0.05$ level. regulation occurs and which external environmental effects are related to these regulatory functions.

\section{The interactions between fungal and soybean}

MAPK cascades during the regulation

of mycorrhizal symbiosis in response to drought stress.

MAPK signal transduction pathways play important roles in mycelium differentiation, symbiotic infection, and stress responses. During fungus-plant interactions, fungal MAPK facilitates fungal infection, whereas plant MAPK stimulates the plant's immune response (Hamel et al. 2012). The presence of AMF induced potato $M A P K$ gene expression at the early and late stages of root colonization (Gallou et al. 2010), as reported by Weidmann and associates (2004) and Grunwald and associates (2004). This study determined that AMF inoculation upregulated the transcript levels of GmMAPK2 and GmMAPK3-2 under normal conditions and of GmMAPK2, GmMAPK3-2, and GmMAPK5 under drought-stress conditions (Fig. 7). However, only the expression levels of GmMAPK2 and GmMAPK5 were increased in nonmycorrhizal soybean roots under drought-stress conditions. Furthermore, when facing drought stress, MAPK genes of AMF, GiMAPK1, and GiMAPK3, were also stimulated (Fig. 8), and it was found that the interaction of mycorrhization and drought stress affected the expression of GmMAPK2, GmMAPK5, and GiMAPK1 based on GMMAPK and GiMAPK transcript levels, which implied that the mycorrhizal fungal and plant MAPK pathways do not function independently. The dialogue between fungal and plant MAPK cascades might have an important regulatory role in the behavior of mycorrhizal soybean, improving its drought tolerance. Drought stress might briefly disrupt the normal symbiotic relationship, inducing the initiation of self-protective mechanisms and the activation of MAPK pathways in both organisms. Subsequently, a new, balanced relationship that is adapted to this drought stress will be established through the regulation of fungus-plant symbiosis by dialogue between the fungal and plant MAPK cascades. However, the deeper mechanisms, especially the molecular mechanisms, require further exploration.

Studies have revealed that, under normal circumstances, AMF inoculation will increase the $\mathrm{H}_{2} \mathrm{O}_{2}$ concentration in a host plant (Huang et al. 2008). This phenomenon reflects the immune response induced in the host plant by mycorrhizal infection. The accumulation of $\mathrm{H}_{2} \mathrm{O}_{2}$ in plants as a result of mycorrhizal infection has been confirmed using DAB staining (Salzer et al. 1999). This study also demonstrated that, under normal conditions, significantly greater $\mathrm{H}_{2} \mathrm{O}_{2}$ concentrations were present in the leaves and roots of mycorrhizal soybean plants than in those of nonmycorrhizal soybean plants (Fig. 2A and B), and the corresponding results for leaves were shown with DAB staining (Fig. 1B). However, under stress produced by adverse environmental conditions, reduction of $\mathrm{H}_{2} \mathrm{O}_{2}$ levels is a method by which mycorrhizal fungi can protect host plants by enhancing the stress resistance of these plants. AMF symbiosis produces a marked direct effect on ROS, and drought stress accentuates the beneficial effects of this symbiotic relationship on plant ROS levels (Hajiboland et al. 2010; Ruiz-Sánchez et al. 2010). Consistent with previous reports, our study confirmed that drought stress induced the significant accumulation of $\mathrm{H}_{2} \mathrm{O}_{2}$ in plants. Under drought conditions, reduced $\mathrm{H}_{2} \mathrm{O}_{2}$ accumulation was observed in soybean subjected to mycorrhizal inoculation compared with nonmycorrhizal soybean, and this reduction was more pronounced in soybean roots than in soybean leaves. Previous reports have suggested that MAPK and $\mathrm{H}_{2} \mathrm{O}_{2}$ play important roles in droughtstress responses and that crosstalk occurs between these molecules. However, under drought conditions, increased GmMAPK and GiMAPK expression and an accompanying reduction in $\mathrm{H}_{2} \mathrm{O}_{2}$ levels were observed in the roots of mycorrhizal soybean plants 
relative to the roots of nonmycorrhizal soybean plants (Figs. 2, 7, and 8). This finding suggested that, in the presence of AMF, GmMAPKs and GiMAPKs may both be involved in reducing $\mathrm{H}_{2} \mathrm{O}_{2}$ level and, thereby, may contribute to the maintenance of ROS equilibrium in soybean plants and the activation of immunity-related physiological responses in these plants.

Under both normal and drought conditions, soluble sugar levels were higher in the roots of mycorrhizal soybean than in the roots of nonmycorrhizal soybean; in addition, especially under drought conditions, significantly higher proline concentrations were observed in the roots of mycorrhizal soybean than in those of nonmycorrhizal soybean (Fig. 3). The accumulation of soluble sugars and proline in the roots of mycorrhizal soybean represents a self-protection strategy of mycorrhizal plant symbiotes that enhances the drought resistance and antioxidant response of these soybean plants.

Increases in soluble sugar concentration can enhance $\mathrm{C}$ supplied to symbiotic fungi and, as discussed above, this may establish a new balance in the relationship between the fungal and plant MAPK signaling pathways, showing adaptation to drought stress. A notable feature of this new relationship is accelerated nutrient exchange (Lee et al. 2012a). There are reports on $\mathrm{N}$ concentration in mycorrhizal plants under stress conditions, we have determined $\mathrm{N}$ concentrations in mycorrhizal soybean and rice under stress conditions as well, and all these supported the role of AMF on the host's improved $\mathrm{N}$ absorption under stress conditions ( $\mathrm{Li}$ et al. 2013b; Liu et al. 2013; Miransari 2010). Exposure to drought stress enhanced the plant-fungus nutrient transmission in mycorrhizal soybean plants, as shown by the significantly upregulated expression of soybean GmSUT1 and fungal GiGS1 and GiAMT2 genes (Fig. 4). The accelerated $\mathrm{C}$ and $\mathrm{N}$ exchange in the newly established symbiotic relationship not only enhances fungal survival by increasing the $\mathrm{C}$ that plants supply to their symbiotic fungi but also increases plant $\mathrm{N}$ absorption and then enhances plant stress tolerance (Liu et al. 2013). Further, mycorrhizal soybean showed better growth status, including plant height, root length, root surface, fresh weight, leaf RWC and cell survival, than nonmycorrhizal soybean (Table 2; Fig. 1A).

In summary, the results in this work demonstrate that, under drought stress, both soybean and AMF MAPK genes were induced, and there existed interactions between mycorrhization and drought stress, which indicated that the mycorrhizal symbiotic relationship in soybean might be regulated by interactive dialogue and coordination between fungal and plant MAPK pathways. Interactions between fungal MAPK and soybean MAPK initiated soybean immune responses to drought, thereby regulating the fungal growth status and the physiological and biochemical parameters of the plants. In particular, drought-stress-induced effects included alterations in fungal infection rates and colonization morphologies in plant roots; changes in the levels of $\mathrm{H}_{2} \mathrm{O}_{2}$, soluble sugars, and proline in plants; and the enhancement of the $\mathrm{C}$ and $\mathrm{N}$ crosstalk between the soybean plants and the symbiotic fungi. These effects resulted in the establishment of a new and balanced symbiotic relationship between the examined plants and fungi and improved the drought tolerance of the soybean and their associated fungal symbionts.

\section{MATERIALS AND METHODS}

Germination and abiotic stress treatments of AMF spores.

The spore material of $G$. intraradices (syn. Rhizophagus irregularis) was purchased from Premier Tech Biotechnologies in units of $10^{6}$. Liquid M medium (Bécard and Fortin 1988) with no $\mathrm{N}$ and phytagel added was poured into 24-well petri dishes. Next, $300 \mu \mathrm{l}$ of spores of $G$. intraradices was added to each well and incubated in the dark at $28^{\circ} \mathrm{C}$. After 5 days, germinated mycelium was observed under the stereomicroscope, and the medium was then carefully removed and replaced with new liquid $\mathrm{M}$ media containing modified N, PEG, and ABA. Four treatments were performed as follows: CK (control treatment), LN (low $\mathrm{N}$ treatment), ABA (hormone treatment), and PEG (drought treatment). For the LN treatment, $1 \mathrm{mM} N$ was contained in the new liquid $\mathrm{M}$ media; $4 \mathrm{mM} \mathrm{N}$ was used for the
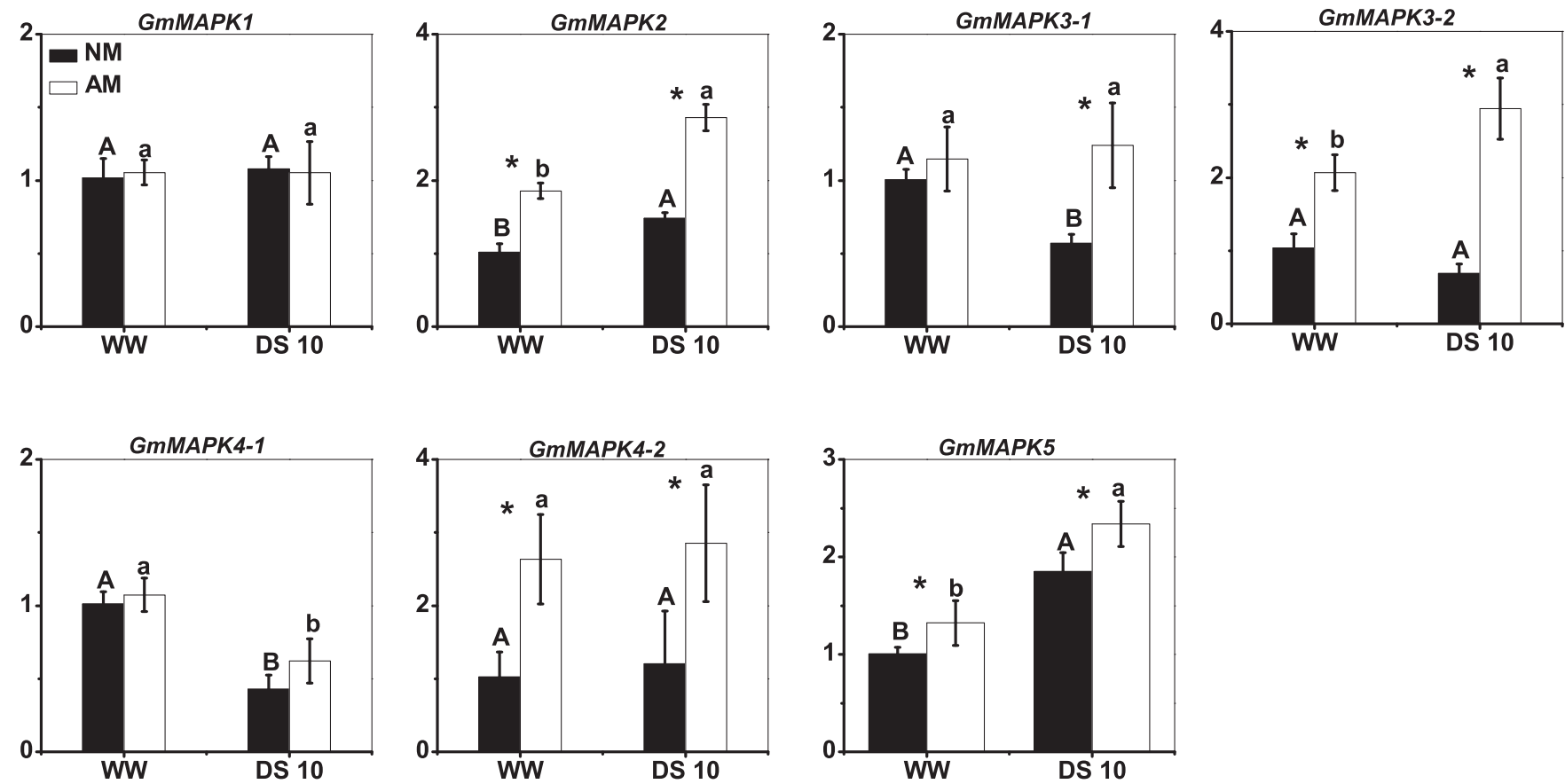

Fig. 7. Relative expression levels of GmMAPKs from soybean (Glycine max) roots under drought-stress conditions. NM = nonmycorrhizal soybean, AM = mycorrhizal soybean, WW = well-watered condition, and DS10 = drought-stressed condition for 10 days. Means followed by the same letter are not significantly different within each treatment. Asterisks indicate significant differences between treatments. Values are means $(n=3) \pm$ standard errors. Means were compared with Duncan's multiple-range test at the $P<0.05$ level. 
other four treatments. For the ABA treatment, the final concentration of ABA was $10 \mu \mathrm{M}$. For the PEG treatment, the new liquid M media contained 25\% PEG 6000 (Sigma-Aldrich Co., Madrid, Spain) to subject the spores to water stress. Each treatment lasted for $24 \mathrm{~h}$ and had three biological replicates.

\section{Plant cultivation and fungal inoculation.}

For the potted experiment, healthy soybean (Glycine max) seed were sterilized with $75 \%$ ethanol and $0.5 \%$ sodium hypochlorite. The sterilized seed were rinsed several times with distilled water and then incubated on germination paper at $28^{\circ} \mathrm{C}$ in the growth chamber. Three days later, germinated seed were transplanted into pots containing $1 \mathrm{~kg}$ of an autoclaved mixture of sand, pearlite, and vermiculite in a volume ratio of 1:1:1; the potted plants were placed into a growth chamber with $75 \%$ humidity and light and dark cycle of 16 and $8 \mathrm{~h}$, respectively, at $25^{\circ} \mathrm{C}$. The plants were watered every other day with Hoagland's nutrition solution with modified phosphorus $(\mathrm{P})$ to $75 \%$ of original concentration to promote mycorrhizal fungal colonization.

The AMF used for inoculation were provided by the Institute of Plant Nutrition and Resource, Beijing Academy of Agriculture and Forestry in China (Glomus intraradices, Bank of Glomales in China, BGC number BGC BJ09). Each mycorrhizal inoculation treatment used $25 \mathrm{~g}$ of inoculum with a spore density of $1,700 \mathrm{ml}^{-1} ; 25 \mathrm{~g}$ of sterilized inoculum and $10 \mathrm{ml}$ of filtered fungal inoculum suspension for inoculation were added to the control pots.

\section{Plant drought-stress treatment.}

Mycorrhizal and nonmycorrhizal soybean plants were subjected to well-watered and drought treatments, with five replicates of each treatment. In the well-watered treatment, plant water supplies remained at $75 \%$ of field capacity for approximately 50 days. In the drought treatment, the supply of water was discontinued for 2 days to reduce the water content to $55 \%$ of field capacity; this water content level was then maintained for the following 8 days, resulting in a total of 10 days of drought treatment. Plant samples were harvested at drought stress by 2 days and 10 days of exposure, respectively. To control drought stress levels, the Thetaprobe TZS-IW soil moisture sensor was used to obtain daily measurements of the water content in the

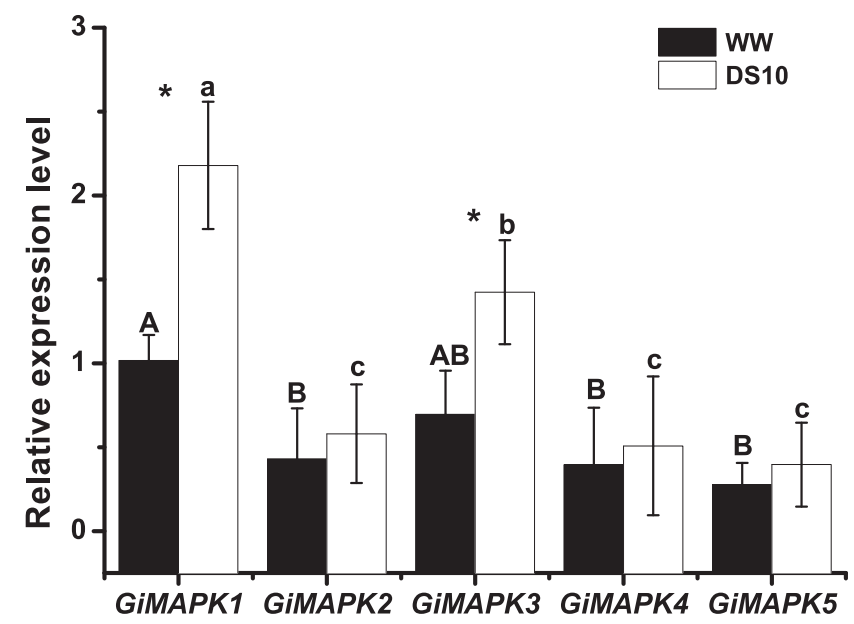

Fig. 8. Relative expression levels of GiMAPKs from mycorrhizal soybean (Glycine max) roots under drought-stress conditions. WW = well-watered condition and DS10 = drought-stressed condition for 10 days. Means followed by the same letter are not significantly different within each treatment. Asterisks indicate significant differences between treatments. Values are means $(n=3) \pm$ standard errors. Means were compared with Duncan's multiple-range test at the $P<0.05$ level. soil matrix (Porcel et al. 2006). This allowed water to be supplied to compensate for daily water loss and ensured the maintenance of a water content level of $55 \%$ in the soil matrix.

\section{Quantitative and qualitative measurement of $\mathrm{H}_{2} \mathrm{O}_{2}$.}

The $\mathrm{H}_{2} \mathrm{O}_{2}$ concentration was determined by chemiluminescence in a ferrocyanide-catalyzed oxidation of luminol, as described by Schwacke and Hager (1992). Each leaf sample $(0.2 \mathrm{~g})$ was ground in liquid $\mathrm{N}$, and $1 \mathrm{ml}$ of $\mathrm{HCIO}_{4}\left(0.2\right.$ mol liter $\left.^{-1}\right)$ was added for 5 min. After centrifugation, the supernatant was collected $(\mathrm{Hu}$ et al. 2009b). Supernatant (100 $\mu \mathrm{l}), 50 \mu \mathrm{l}$ of luminol (5-amino-2, 3dihydro-1, 4-phthalazinedione), and $800 \mu \mathrm{l}$ of phosphate-buffered saline were mixed and added to $100 \mu \mathrm{l}$ of $\mathrm{K}_{3}\left[\mathrm{Fe}(\mathrm{CN})_{6}\right]$ to initiate the reaction. One unit of $\mathrm{H}_{2} \mathrm{O}_{2}$ was defined as the chemiluminescence that resulted from the internal standard of $\mathrm{H}_{2} \mathrm{O}_{2}$ at $1 \mu \mathrm{M} / \mathrm{g}$ fresh weight.

Qualitative visual observations of $\mathrm{H}_{2} \mathrm{O}_{2}$ concentration were obtained using the DAB staining approach (Orozco-Cardenas and Ryan 1999). Briefly, the $\mathrm{pH}$ of an appropriate quantity of DAB dye $\left(1 \mathrm{mg} \mathrm{ml}^{-1}\right.$; $\left.\mathrm{pH} 3.8\right)$ was adjusted to $\mathrm{pH} 5.8$ using $\mathrm{NaOH}$. This DAB dye was added to pretreated soybean, which were then incubated in the dark at $28^{\circ} \mathrm{C}$ for $8 \mathrm{~h}$. After this incubation, the DAB dye was aspirated off of the soybean, $95 \%$ ethanol was added, and the resulting sample was boiled for 10 min to remove the chlorophyll. The sample was then transferred to anhydrous ethanol, which preserved the sample for subsequent observation and photography.

Quantification of proline and soluble sugar concentrations.

In accordance with previously described procedures, free proline was first extracted from samples then quantified using spectrophotometric observations of chromogenic reactions with ninhydrin at $515 \mathrm{~nm}$ (Bates et al. 1973). The concentration of soluble sugar was determined using the method described by Yemm and Willis (1954). Briefly, $0.1 \mathrm{~g}$ of fresh sample was weighed, extracted three times using $70 \%$ ethanol, and adjusted to a volume of $50 \mathrm{ml}$. Subsequently, $1 \mathrm{ml}$ of the sample solution was obtained and placed in an ice bath, and $5 \mathrm{ml}$ of anthrone$\mathrm{H}_{2} \mathrm{SO}_{4}$ chromogenic reagent was added to the sample aliquot. The resulting solution was then incubated in a boiling water bath for precisely $10 \mathrm{~min}$ and cooled to room temperature using running water. Colorimetric measurements of this solution at $620 \mathrm{~nm}$ were then acquired using an ultraviolet spectrophotometer.

\section{Determination of the RWC and the extent of drought-induced cell death.}

The RWC was determined using a gravimetric approach (Smart 1974). Briefly, recently picked leaves were weighed to determine their fresh weight $(\mathrm{FW})$. These leaves were then soaked in water for 4 to $6 \mathrm{~h}$ and reweighed to determine their turgid fresh weight $(\mathrm{TW})$. The leaves were then placed in a $105^{\circ} \mathrm{C}$ oven and dried at $80^{\circ} \mathrm{C}$ for $24 \mathrm{~h}$. The weight of the resulting leaves was called the dry weight (DW). The RWC of the leaves was then calculated as follows: $\mathrm{RWC}=(\mathrm{FW}-\mathrm{DW}) /$ $(\mathrm{TW}-\mathrm{DW}) \times 100 \%$.

Drought-induced cell death was analyzed using the trypan blue staining method described by Pogány and associates (2004). Briefly, a trypan blue stock solution was created by mixing $10 \mathrm{~g}$ of phenol, $10 \mathrm{ml}$ of glycerol, $10 \mathrm{ml}$ of lactic acid, $10 \mathrm{ml}$ of distilled water, and $0.02 \mathrm{~g}$ of trypan blue (Sigma). This stock solution was then diluted with ethanol $(96 \%, 1: 2$, vol/vol) to create the working solution. Leaves were processed by immersion in the working solution, heating in a boiling water bath for $1 \mathrm{~min}$, and then incubation in the working solution for 1 day. After this incubation, the leaves were transferred to a saturated chloral hydrate solution $(50 \mathrm{~g}$ of chloral hydrate dissolved in $20 \mathrm{ml}$ of distilled water), bleached, observed, and photographed. 
Plant growth parameter determination and calculation of the AMF colonization rate.

After plants were harvested, plant height was recorded by flexible ruler. The length and surface area of roots were detected using the Root scan analysis system WinRHIZO. The shoot and root systems were separated, and the root and shoot dry weights were determined after oven drying at $75^{\circ} \mathrm{C}$ for $48 \mathrm{~h}$. AM colonization was calculated according to Phillips and Hayman (1970). Soybean root segments were cut into 0.5- to $1.0-\mathrm{cm}$ pieces and stained with trypan blue, and mycorrhizal colonization was determined according to Trouvelot and associates (1986).

\section{MAPK genes in AMF sequence retrieval, alignment, and phylogenetic trees.}

Homology searches were performed using BLASTp tool and protein databases (NCBI server), using the amino acid sequence of MAPK genes from $S$. cerevisiae as an initial query to create an alignment. To search for Sce-Hog1-like proteins, the Sce-Hog1 domain sequences of the MAPK gene from $S$. cerevisiae, found in the first search, were used as queries. All of the identified sequences used for alignments are listed in Supplementary Table 1 . The domains within each sequence were analyzed with SMART. The MAPK genes from fungi and S. cerevisiae were aligned by ClustalX (1.8). Neighbor-joining trees were constructed by MEGA 5.0 with bootstrap 1,000 .

\section{Gene expression by using qRT-PCR.}

Total RNA was extracted from germinated spores (approximately 7,500 spores) and fresh roots (approximately $100 \mathrm{mg}$ ) using Trizol reagent plus RNA Purification Kit (Invitrogen, Carlsbad, CA, U.S.A.), including the DNase treatment, according to the manufacturer's protocol. Total RNA was quantified using a spectrophotometer following electrophoresis on a $0.8 \%$ (wt/vol) agarose gel to assess the concentration and integrity of the sample. Approximately $1 \mu \mathrm{g}$ of total RNA was transcribed into cDNA using Superscript III reverse transcription (Invitrogen, Karlsruhe, Germany). The quality of the cDNA was assessed through qRT-PCR using primers of the $\beta$-tublin gene for soybean and $\mathrm{S} 4$ ribosomal protein for the fungi.

qRT-PCR was performed using the Agilent Mx3000P Analyzer (Agilent Technologies Ltd., Santa Clara, CA, U.S.A.) in a $15-\mu \mathrm{l}$ reaction volume $(1 \mu \mathrm{l}$ of cDNA, $1 \mu \mathrm{l}$ of primer mix, and $7.5 \mu \mathrm{l}$ of SYBR Green Master Mix) (Agilent Technologies Ltd.). qRT-PCR was performed on three independent biological samples and three technical replicates. Primers for qRT-PCR were designed using the Primer Premier software (version 5.0; PREMIER Biosoft) or derived from the literature (primers for GiAMT2, GiGS1, and GiSR4), and all primer sequences are shown in Supplementary Table S3. Primer sequences were blasted on the NCBI databases and soybean's MAPK sequences were selected according to the reference (Neupane et al. 2013). For soybean, $\beta$-tublin was used as the reference gene (Hu et al. 2009a) and the fungal gene expression results were normalized using the $\mathrm{S} 4$ ribosomal protein as a reference gene due to its high expression stability (Tian et al. 2010). The comparative $\Delta \Delta$-cycle threshold method was used to measure changes in the expression of selected genes relative to untreated controls (Winer et al. 1999).

\section{Statistical analysis.}

Student's $t$ test was performed for data from the spores' experiment and mycorrhizal colonization, whereas two-way ANOVA was performed for other data, using the SPSS software program (13.0). Duncan's multiple-range test was performed to make comparisons between treatments. Data were expressed as the means \pm standard errors of observations from independent experiments. Values were based on three biological replicates for each treatment, and $P<0.05$ was considered to be significant.

\section{ACKNOWLEDGMENTS}

This work is supported by Natural Science Foundation of China (NSFC) (31370144), Strategic Priority Research Program of the Chinese Academy of Sciences (CAS) (XDB1503010), the Natural Science Foundation of Jilin Province (20130101080JC and 20140101017JC), Science Foundation of Chinese Academy of Sciences (KZZD-EW-TZ-16), and One Hundred Talents Program of CAS (Y2H102).

\section{LITERATURE CITED}

Abbaspour, H., Saeidi-Sar, S., Afshari, H., and Abdel-Wahhab, M. A. 2012. Tolerance of mycorrhiza infected pistachio (Pistacia vera L.) seedling to drought stress under glasshouse conditions. J. Plant Physiol. 169: 704-709.

Ahuja, I., de Vos, R. C., Bones, A. M., and Hall, R. D. 2010. Plant molecular stress responses face climate change. Trends Plant Sci. 15:664-674.

Aldape, M. J., Elmer, A. M., Chao, W. S., and Grimes, H. D. 2003. Identification and characterization of a sucrose transporter isolated from the developing cotyledons of soybean. Arch. Biochem. Biophys. 409: 243-250.

Allen, M. F. 2007. Mycorrhizal fungi: Highways for water and nutrients in arid soils. Vadose Zone J. 6:291-297.

Aroca, R., Vernieri, P., and Ruiz-Lozano, J. M. 2008. Mycorrhizal and nonmycorrhizal Lactuca sativa plants exhibit contrasting responses to exogenous ABA during drought stress and recovery. J. Exp. Bot. 59: 2029-2041.

Asai, S., Ohta, K., and Yoshioka, H. 2008. MAPK signaling regulates nitric oxide and NADPH oxidase-dependent oxidative bursts in Nicotiana benthamiana. Plant Cell 20:1390-1406.

Bárzana, G., Aroca, R., Bienert, G. P., Chaumont, F., and Ruiz-Lozano, J. M. 2014. New insights into the regulation of aquaporins by the arbuscular mycorrhizal symbiosis in maize plants under drought stress and possible implications for plant performance. Mol. Plant-Microbe Interact. 27:349-363.

Bates, L. S., Waldren, R. P., and Teare, I. D. 1973. Rapid determination of free proline for water-stress studies. Plant Soil 39:205-207.

Bécard, G., and Fortin, J. A. 1988. Early events of vesicular-arbuscular mycorrhiza formation on Ri T-DNA transformed roots. New Phytol. 108: 211-218.

Buchanan, B. B., and Balmer, Y. 2005. Redox regulation: A broadening horizon. Annu. Rev. Plant Biol. 56:187-220.

Chen, R. E., and Thorner, J. 2007. Function and regulation in MAPK signaling pathways: Lessons learned from the yeast Saccharomyces cerevisiae. Biochim. Biophys. Acta 1773:1311-1340.

Colcombet, J., and Hirt, H. 2008. Arabidopsis MAPKs: A complex signalling network involved in multiple biological processes. Biochem. J. 413:217-226

Dixon, K. P., Xu, J. R., Smirnoff, N., and Talbot, N. J. 1999. Independent signaling pathways regulate cellular turgor during hyperosmotic stress and appressorium-mediated plant infection by Magnaporthe grisea. Plant Cell 11:2045-2058.

Droillard, M., Boudsocq, M., Barbier-Brygoo, H., and Laurière, C. 2002. Different protein kinase families are activated by osmotic stresses in Arabidopsis thaliana cell suspensions. Involvement of the MAP kinases AtMPK3 and AtMPK6. FEBS (Fed. Eur. Biochem. Soc.) Lett. 527:43-50.

Foyer, C. H., and Shigeoka, S. 2011. Understanding oxidative stress and antioxidant functions to enhance photosynthesis. Plant Physiol. 155:93100.

Francia, D., Chiltz, A., Lo Schiavo, F., Pugin, A., Bonfante, P., and Cardinale, F. 2011. AM fungal exudates activate MAP kinases in plant cells in dependence from cytosolic $\left.\mathrm{Ca}^{2+}\right)$ increase. Plant Physiol. Biochem. 49:963-969.

Gallou, A., De Jaeger, N., Cranenbrouck, S., and Declerck, S. 2010. Fast track in vitro mycorrhization of potato plantlets allow studies on gene expression dynamics. Mycorrhiza 20:201-207.

Govindarajulu, M., Pfeffer, P. E., Jin, H., Abubaker, J., Douds, D. D., Allen, J. W., Bücking, H., Lammers, P. J., and Shachar-Hill, Y. 2005. Nitrogen transfer in the arbuscular mycorrhizal symbiosis. Nature 435:819-823.

Grunwald, U., Nyamsuren, O., Tamasloukht, M., Lapopin, L., Becker, A., Mann, P., Gianinazzi-Pearson, V., Krajinski, F., and Franken, P. 
2004. Identification of mycorrhiza-regulated genes with arbuscule development-related expression profile. Plant Mol. Biol. 55:553-566.

Hajiboland, R., Aliasgharzadeh, N., Laiegh, S., and Poschenrieder, C. 2010. Colonization with arbuscular mycorrhizal fungi improves salinity tolerance of tomato (Solanum lycopersicum L.) plants. Plant Soil 331:313-327.

Hamel, L. P., Nicole, M. C., Duplessis, S., and Ellis, B. E. 2012. Mitogenactivated protein kinase signaling in plant-interacting fungi: Distinct messages from conserved messengers. Plant Cell 24:1327-1351.

Harb, A., Krishnan, A., Ambavaram, M. M. R., and Pereira, A. 2010. Molecular and physiological analysis of drought stress in Arabidopsis reveals early responses leading to acclimation in plant growth. Plant Physiol. 154:1254-1271.

Hu, R., Fan, C., Li, H., Zhang, Q., and Fu, Y.-F. 2009a. Evaluation of putative reference genes for gene expression normalization in soybean by quantitative real-time RT-PCR. BMC Mol. Biol. 10:93.

$\mathrm{Hu}$, X., Neill, S. J., Yang, Y., and Cai, W. 2009b. Fungal elicitor Pep-25 increases cytosolic calcium ions, $\mathrm{H}_{2} \mathrm{O}_{2}$ production and activates the octadecanoid pathway in Arabidopsis thaliana. Planta 229:1201-1208.

Huang, L. L., Yang, C., Zhao, Y., Xu, X., Xu, Q., Li, G. Z., Cao, J., Herbert, S. J., and Hao, L. 2008. Antioxidant defenses of mycorrhizal fungus infection against $\mathrm{SO}_{2}$ )-induced oxidative stress in Avena nuda seedlings. Bull. Environ. Contam. Toxicol. 81:440-444.

Huang, X. S., Luo, T., Fu, X. Z., Fan, Q. J., and Liu, J. H. 2011. Cloning and molecular characterization of a mitogen-activated protein kinase gene from Poncirus trifoliata whose ectopic expression confers dehydration/ drought tolerance in transgenic tobacco. J. Exp. Bot. 62:5191-5206.

Idnurm, A., and Howlett, B. J. 2001. Pathogenicity genes of phytopathogenic fungi. Mol. Plant Pathol. 2:241-255.

Im, J. H., Lee, H., Kim, J., Kim, H. B., and An, C. S. 2012. Soybean MAPK, GMK1 is dually regulated by phosphatidic acid and hydrogen peroxide and translocated to nucleus during salt stress. Mol. Cells 34:271-278.

Jonak, C., Okrész, L., Bögre, L., and Hirt, H. 2002. Complexity, cross talk and integration of plant MAP kinase signalling. Curr. Opin. Plant Biol. 5: 415-424.

Lee, B. R., Muneer, S., Avice, J. C., Jung, W. J., and Kim, T. H. 2012a. Mycorrhizal colonisation and P-supplement effects on $\mathrm{N}$ uptake and $\mathrm{N}$ assimilation in perennial ryegrass under well-watered and droughtstressed conditions. Mycorrhiza 22:525-534.

Lee, B. R., Muneer, S., Jung, W. J., Avice, J. C., Ourry, A., and Kim, T. H. 2012b. Mycorrhizal colonization alleviates drought-induced oxidative damage and lignification in the leaves of drought-stressed perennial ryegrass (Lolium perenne). Physiol. Plant. 145:440-449.

Li, T., Hu, Y. J., Hao, Z. P., Li, H., Wang, Y. S., and Chen, B. D. 2013a. First cloning and characterization of two functional aquaporin genes from an arbuscular mycorrhizal fungus Glomus intraradices. New Phytol. 197: 617-630.

Li, Y. J., Liu, Z. L., Hou, H. Y., Lei, H., Zhu, X. C., Li, X. H., He, X. Y., and Tian, C. J. 2013b. Arbuscular mycorrhizal fungi-enhanced resistance against Phytophthora sojae infection on soybean leaves is mediated by a network involving hydrogen peroxide, jasmonic acid, and the metabolism of carbon and nitrogen. Acta Physiol. Plant. 35:3465-3475.

Liu, J. Z., Horstman, H. D., Braun, E., Graham, M. A., Zhang, C., Navarre, D., Qiu, W. L., Lee, Y., Nettleton, D., Hill, J. H., and Whitham, S. A. 2011. Soybean homologs of MPK4 negatively regulate defense responses and positively regulate growth and development. Plant Physiol. 157: 1363-1378.

Liu, Z. L., Li, Y. J., Hou, H. Y., Zhu, X. C., Rai, V., He, X. Y., and Tian, C. J. 2013. Differences in the arbuscular mycorrhizal fungi-improved rice resistance to low temperature at two $\mathrm{N}$ levels: Aspects of $\mathrm{N}$ and $\mathrm{C}$ metabolism on the plant side. Plant Physiol. Biochem. 71:87-95.

Madhani, H. D., and Fink, G. R. 1998. The riddle of MAP kinase signaling specificity. Trends Genet. 14:151-155.

Martin, F., Aerts, A., Ahrén, D., Brun, A., Danchin, E. G., Duchaussoy, F. Gibon, J., Kohler, A., Lindquist, E., Pereda, V., Salamov, A., Shapiro, H. J., Wuyts, J., Blaudez, D., Buée, M., Brokstein, P., Canbäck, B., Cohen, D., Courty, P. E., Coutinho, P. M., Delaruelle, C., Detter, J. C., Deveau, A., DiFazio, S., Duplessis, S., Fraissinet-Tachet, L., Lucic, E., Frey-Klett, P., Fourrey, C., Feussner, I., Gay, G., Grimwood, J., Hoegger, P. J., Jain, P., Kilaru, S., Labbé, J., Lin, Y. C., Legué, V., Le Tacon, F., Marmeisse, R., Melayah, D., Montanini, B., Muratet, M., Nehls, U., Niculita-Hirzel, H., Oudot-Le Secq, M. P., Peter, M., Quesneville, H., Rajashekar, B., Reich, M., Rouhier, N., Schmutz, J., Yin, T., Chalot, M., Henrissat, B., Kües, U., Lucas, S., Van de Peer, Y., Podila, G. K., Polle, A., Pukkila, P. J., Richardson, P. M., Rouzé, P., Sanders, I. R., Stajich, J. E., Tunlid, A., Tuskan, G., and Grigoriev, I. V. 2008. The genome of Laccaria bicolor provides insights into mycorrhizal symbiosis. Nature 452:88-92.

Martin, F., Kohler, A., Murat, C., Balestrini, R., Coutinho, P. M., Jaillon, O., Montanini, B., Morin, E., Noel, B., Percudani, R., Porcel, B., Rubini, A.,
Amicucci, A., Amselem, J., Anthouard, V., Arcioni, S., Artiguenave, F. Aury, J. M., Ballario, P., Bolchi, A., Brenna, A., Brun, A., Buée, M., Cantarel, B., Chevalier, G., Couloux, A., Da Silva, C., Denoeud, F., Duplessis, S., Ghignone, S., Hilselberger, B., Iotti, M., Marçais, B., Mello, A., Miranda, M., Pacioni, G., Quesneville, H., Riccioni, C., Ruotolo, R., Splivallo, R., Stocchi, V., Tisserant, E., Viscomi, A. R., Zambonelli, A., Zampieri, E., Henrissat, B., Lebrun, M. H., Paolocci, F., Bonfante, P., Ottonello, S., and Wincker, P. 2010. Périgord black truffle genome uncovers evolutionary origins and mechanisms of symbiosis. Nature 464:1033-1038.

Matsuoka, D., Nanmori, T., Sato, K., Fukami, Y., Kikkawa, U., and Yasuda, T. 2002. Activation of AtMEK1, an Arabidopsis mitogen-activated protein kinase kinase, in vitro and in vivo: Analysis of active mutants expressed in $E$. coli and generation of the active form in stress response in seedlings. Plant J. 29:637-647.

Menotta, M., Pierleoni, R., Amicucci, A., Sisti, D., Cerasi, A., Millo, E., Chiarantini, L., and Stocchi, V. 2006. Characterization and complementation of a Fus3/Kss1 type MAPK from Tuber borchii, TBMK. Mol. Genet. Genomics 276:126-134.

Miransari, M. 2010. Contribution of arbuscular mycorrhizal symbiosis to plant growth under different types of soil stress. Plant Biol. (Stuttg.) 12: 563-569.

Nakashima, K., Yamaguchi-Shinozaki, K., and Shinozaki, K. 2014. The transcriptional regulatory network in the drought response and its crosstalk in abiotic stress responses including drought, cold, and heat. Front. Plant Sci. 5: Article 170.

Neupane, A., Nepal, M. P., Piya, S., Subramanian, S., Rohila, J. S., Reese, R. N., and Benson, B. V. 2013. Identification, nomenclature, and evolutionary relationships of mitogen-activated protein kinase (MAPK) genes in soybean. Evol. Bioinform. Online 9:363-386.

Orozco-Cardenas, M., and Ryan, C. A. 1999. Hydrogen peroxide is generated systemically in plant leaves by wounding and systemin via the octadecanoid pathway. Proc. Natl. Acad. Sci. U.S.A. 96:6553-6557.

Perez-Moreno, J., and Read, D. J. 2001. Nutrient transfer from soil nematodes to plants: A direct pathway provided by the mycorrhizal mycelial network. Plant Cell Environ. 24:1219-1226.

Pérez-Tienda, J., Testillano, P. S., Balestrini, R., Fiorilli, V., Azcón-Aguilar, C., and Ferrol, N. 2011. GintAMT2, a new member of the ammonium transporter family in the arbuscular mycorrhizal fungus Glomus intraradices. Fungal Genet. Biol. 48:1044-1055.

Peter, M., Courty, P.-E., Kohler, A., Delaruelle, C., Martin, D., Tagu, D., Frey-Klett, P., Duplessis, S., Chalot, M., Podila, G., and Martin, F. 2003. Analysis of expressed sequence tags from the ectomycorrhizal basidiomycetes Laccaria bicolor and Pisolithus microcarpus. New Phytol. 159:117-129.

Phillips, J. M., and Hayman, D. S. 1970. Improved procedures for clearing roots and staining parasitic and vesicular-arbuscular mycorrhizal fungi for rapid assessment of infection. Trans. Br. Mycol. Soc. 55:158-161, IN16-IN18.

Pitzschke, A., Schikora, A., and Hirt, H. 2009a. MAPK cascade signalling networks in plant defence. Curr. Opin. Plant Biol. 12:421-426.

Pitzschke, A., Djamei, A., Bitton, F., and Hirt, H. 2009b. A major role of the MEKK1-MKK1/2-MPK4 pathway in ROS signalling. Mol. Plant 2: 120-137.

Pogány, M., Koehl, J., Heiser, I., Elstner, E. F., and Barna, B. 2004. Juvenility of tobacco induced by cytokinin gene introduction decreases susceptibility to Tobacco necrosis virus and confers tolerance to oxidative stress. Physiol. Mol. Plant Pathol. 65:39-47.

Porcel, R., Aroca, R., Cano, C., Bago, A., and Ruiz-Lozano, J. M. 2006. Identification of a gene from the arbuscular mycorrhizal fungus Glomus intraradices encoding for a 14-3-3 protein that is up-regulated by drought stress during the AM symbiosis. Microb. Ecol. 52:575-582.

Rentel, M. C., Lecourieux, D., Ouaked, F., Usher, S. L., Petersen, L., Okamoto, H., Knight, H., Peck, S. C., Grierson, C. S., Hirt, H., and Knight, M. R. 2004. OXI1 kinase is necessary for oxidative burstmediated signalling in Arabidopsis. Nature 427:858-861.

Rispail, N., Soanes, D. M., Ant, C., Czajkowski, R., Grünler, A., Huguet, R., Perez-Nadales, E., Poli, A., Sartorel, E., Valiante, V., Yang, M. Beffa, R., Brakhage, A. A., Gow, N. A., Kahmann, R., Lebrun, M. H., Lenasi, H., Perez-Martin, J., Talbot, N. J., Wendland, J., and Di Pietro, A. 2009. Comparative genomics of MAP kinase and calcium-calcineurin signalling components in plant and human pathogenic fungi. Fungal Genet. Biol. 46:287-298.

Ruiz-Lozano, J. M. 2003. Arbuscular mycorrhizal symbiosis and alleviation of osmotic stress. New perspectives for molecular studies. Mycorrhiza 13:309-317.

Ruiz-Lozano, J. M., Porcel, R., and Aroca, R. 2006. Does the enhanced tolerance of arbuscular mycorrhizal plants to water deficit involve modulation of drought-induced plant genes? New Phytol. 171:693-698. 
Ruiz-Sánchez, M., Aroca, R., Muñoz, Y., Polón, R., and Ruiz-Lozano, J. M. 2010. The arbuscular mycorrhizal symbiosis enhances the photosynthetic efficiency and the antioxidative response of rice plants subjected to drought stress. J. Plant Physiol. 167:862-869.

Salzer, P., Corbière, H., and Boller, T. 1999. Hydrogen peroxide accumulation in Medicago truncatula roots colonized by the arbuscular mycorrhiza-forming fungus Glomus intraradices. Planta 208:319-325.

Schüßler, A., Schwarzott, D., and Walker, C. 2001. A new fungal phylum, the Glomeromycota: Phylogeny and evolution. Mycol. Res. 105: 1413-1421.

Schwacke, R., and Hager, A. 1992. Fungal elicitors induce a transient release of active oxygen species from cultured spruce cells that is dependent on $\left.\mathrm{Ca}^{2+}{ }^{2+}\right)$ and protein-kinase activity. Planta 187:136-141.

Sharma, S., and Verslues, P. E. 2010. Mechanisms independent of abscisic acid (ABA) or proline feedback have a predominant role in transcriptional regulation of proline metabolism during low water potential and stress recovery. Plant Cell Environ. 33:1838-1851.

Smart, R. E. 1974. Rapid estimates of relative water content. Plant Physiol. 53:258-260.

Szabados, L., and Savouré, A. 2010. Proline: A multifunctional amino acid. Trends Plant Sci. 15:89-97.

Tian, C., Kasiborski, B., Koul, R., Lammers, P. J., Bücking, H., and ShacharHill, Y. 2010. Regulation of the nitrogen transfer pathway in the arbuscular mycorrhizal symbiosis: Gene characterization and the coordination of expression with nitrogen flux. Plant Physiol. 153:1175-1187.

Tisserant, E., Kohler, A., Dozolme-Seddas, P., Balestrini, R., Benabdellah, K., Colard, A., Croll, D., Da Silva, C., Gomez, S. K., Koul, R., Ferrol, N., Fiorilli, V., Formey, D., Franken, P., Helber, N., Hijri, M., Lanfranco, L., Lindquist, E., Liu, Y., Malbreil, M., Morin, E., Poulain, J., Shapiro, H., van Tuinen, D., Waschke, A., Azcón-Aguilar, C., Bécard, G., Bonfante, P., Harrison, M. J., Küster, H., Lammers, P., Paszkowski, U., Requena, N., Rensing, S. A., Roux, C., Sanders, I. R., Shachar-Hill, Y., Tuskan, G., Young, J. P., Gianinazzi-Pearson, V., and Martin, F. 2012. The transcriptome of the arbuscular mycorrhizal fungus Glomus intraradices (DAOM 197198) reveals functional tradeoffs in an obligate symbiont. New Phytol. 193:755-769.

Tisserant, E., Malbreil, M., Kuo, A., Kohler, A., Symeonidi, A., Balestrini, R., Charron, P., Duensing, N., Frei dit Frey, N., Gianinazzi-Pearson, V., Gilbert, L. B., Handa, Y., Herr, J. R., Hijri, M., Koul, R., Kawaguchi, M., Krajinski, F., Lammers, P. J., Masclaux, F. G., Murat, C., Morin, E., Ndikumana, S., Pagni, M., Petitpierre, D., Requena, N., Rosikiewicz, P., Riley, R., Saito, K., San Clemente, H., Shapiro, H., van Tuinen, D., Bécard, G., Bonfante, P., Paszkowski, U., Shachar-Hill, Y. Y., Tuskan, G. A., Young, J. P. W., Sanders, I. R., Henrissat, B., Rensing, S. A., Grigoriev, I. V., Corradi, N., Roux, C., and Martin, F. 2013. Genome of an arbuscular mycorrhizal fungus provides insight into the oldest plant symbiosis. Proc. Natl. Acad. Sci. U.S.A. 110:20117-20122.

Trouvelot, A., Fardeau, J. C., Plenchette, C., Gianinazzi, S., and Gianinazzapearson, V. 1986. Nutritional balance and symbiotic expression in mycorrhizal wheat. Physiol. Veg. 24:300.

Umezawa, T., Fujita, M., Fujita, Y., Yamaguchi-Shinozaki, K., and Shinozaki, K. 2006. Engineering drought tolerance in plants: Discovering and tailoring genes to unlock the future. Curr. Opin. Biotechnol. 17:113-122.

Verslues, P. E., and Sharma, S. 2010. Proline metabolism and its implications for plant-environment interaction. Arabidopsis Book 8:e0140 10.1199/ tab.0140.

Weidmann, S., Sanchez, L., Descombin, J., Chatagnier, O., Gianinazzi, S., and Gianinazzi-Pearson, V. 2004. Fungal elicitation of signal transduction-related plant genes precedes mycorrhiza establishment and requires the dmi3 gene in Medicago truncatula. Mol. Plant-Microbe Interact. 17:1385-1393.

Winer, J., Jung, C. K., Shackel, I., and Williams, P. M. 1999. Development and validation of real-time quantitative reverse transcriptase-polymerase chain reaction for monitoring gene expression in cardiac myocytes in vitro. Anal. Biochem. 270:41-49.

Xiong, L., and Yang, Y. 2003. Disease resistance and abiotic stress tolerance in rice are inversely modulated by an abscisic acid-inducible mitogen-activated protein kinase. Plant Cell 15:745-759.

Yang, S., Vanderbeld, B., Wan, J., and Huang, Y. 2010. Narrowing down the targets: Towards successful genetic engineering of drought-tolerant crops. Mol. Plant 3:469-490.

Yang, H., Dai, Y., Wang, X., Zhang, Q., Zhu, L., and Bian, X. 2014. Metaanalysis of interactions between arbuscular mycorrhizal fungi and biotic stressors of plants. Sci. World J. 2014: Article ID 746506. http://dx.doi. org/10.1155/2014/746506.

Yemm, E. W., and Willis, A. J. 1954. The estimation of carbohydrates in plant extracts by anthrone. Biochem. J. 57:508-514.

Zhang, A., Jiang, M., Zhang, J., Tan, M., and Hu, X. 2006. Mitogenactivated protein kinase is involved in abscisic acid-induced antioxidant defense and acts downstream of reactive oxygen species production in leaves of maize plants. Plant Physiol. 141:475-487.

Zhao, X., Mehrabi, R., and Xu, J. R. 2007. Mitogen-activated protein kinase pathways and fungal pathogenesis. Eukaryot. Cell 6:1701-1714.

\section{AUTHOR-RECOMMENDED INTERNET RESOURCES}

NCBI server: www.ncbi.nlm.nih.gov/

SMART: smart.embl-heidelberg.de/ 